\title{
OPTIMUM CONDITION OF BIOETANOL PRODUCTION VIA ACIDIC HYDROLYSIS FROM PINEAPLE (Ananas comosus Merr.) PEEL WASTE IN KUALU VILLAGE-KAMPAR
}

\author{
Rahmiwati Hilma, Unggul Akbar, Prasetya \\ Program Studi Kimia, Fakultas MIPA dan Kesehatan, \\ Universitas Muhammadiyah Riau \\ Email Koresponden : rahmiwatihilma@umri.ac.id
}

\section{ABSTRACT}

Bioethanol is an alternative and potential fuel derived from plants, which has the ability to reduce $\mathrm{CO}_{2}$ emissions. It contains sugar that can be utilized and processed into bioethanol. This study aims to produce bioethanol from pineapple peel (Ananas comosus Merr.) through acidic hydrolysis and fermentation process using Sacharomyces cereviceae. This research was expected to know the optimum condition of $S$. Cereviceae mass and the time of fermentation on the conversion of pineapple peel into bioethanol towards amount and content of ethanol produced. The hydrolysis was using sulfuric acid $\left(\mathrm{H}_{2} \mathrm{SO}_{4}\right)$, fermented with variations yeast 20, 40 and 60 gram and 2, 4 and 6 days of time variations. The resulting bioethanol was purified using a distillation process, then analyzed by gas chromatography. The results showed that optimum ethanol content was obtain in yeasts 20 and 40 grams and 2 days of fermentation. The resulting ethanol content was $26.3 \%$ and $24.6 \%$.

\section{Keywords: Menstruation Pineapple (Ananas comosus Merr.), Hydrolysis, Ethanol, Gas Chromatography}

\section{PENDAHULUAN}

Saat ini kecendrungan pemakaian bahan bakar semakin tinggi sedangkan sumber bahan bakar minyak bumi yang dipakai saat ini semakin menipis. Bioetanol dapat digunakan sebagai bahan bakar untuk pemecahan masalah energi pada saat ini (Retno et. al, 2011).

Bioetanol adalah bahan bakar transportasi yang unik, lebih ekonomis, lebih ramah lingkungan, bisa meningkatkan angka Oktan serta sifat sifatnya yang non-toksik, membuatnya menarik untuk diteliti lebih lanjut (Ali dan Zulkali, 2013). Bioetanol memiliki kelebihan selain ramah lingkungan, penggunaannya juga dapat mengurangi emisi karbon monoksida dan asap lainnya dari kendaraan (Komarayati et. al, 2011).

Produksi etanol dengan metode fermentasi dapat dilakukan dengan berbagai macam bahan baku yang mengandung gula reduksi. Salah satu bahan baku yang digunakan yaitu kulit nenas (Ananas comosus Merr.),. Kandungan gula reduksi pada filtrat kulit nenas sebesar 11,40\%. Kandungan gula yang cukup tinggi pada kulit nenas tersebut memungkinkan untuk dimanfaatkan sebagai bahan baku pembuatan bioetanol melalui proses fermentasi. Berdasarkan hasil survey di lapangan, beberapa usaha produksi Rumah Tangga olahan keripik nenas di desa Kualu, Riau memiliki kapasitas rata-rata 12$15 \mathrm{~kg} / \mathrm{hari}$, dengan jumlah nenas yang digunakan sebagai bahan baku sekitar $200 \mathrm{~kg} / \mathrm{hari}$. Limbah kulit nenas yang dihasilkan dapat mencapai 40$50 \mathrm{~kg} /$ hari (Oktaviani et. al, 2013). Hal ini menjadi potensi untuk dikembangkan, karena selain bisa mengurangi limbah kulit nenas juga bisa dimanfaatkan untuk produksi bioetanol. Penelitian sebelumnya oleh Setyawati dan astuti (2010), melakukan penelitian bioetanol dari kulit nenas dengan menggunakan Saccharomyces cereviceae dan memvariasikan waktu fermentasi untuk mendapatkan kadar bioetanol yang optimal. Hasil penelitian yang diperolehnya hanya mendapatkan yaitu kadar etanol tertinggi sebesar 3,965\%.

Tahapan penelitian yang dilakukan dalam proses pengolahan bioetanol adalah proses hidrolisa selulosa pada kulit nenas dengan menggunakan larutan asam encer. Setelah pemecahan ikatan rantai karbohidrat digunakan proses fermentasi oleh S.cereviceae. Masyarakat memanfaatkan S.cereviceae sebagai fermentasi, baik dalam makanan maupun minuman yang mengandung alkohol. Jenis mikroba ini mampu 
mengubah cairan yang mengandung gula menjadi alkohol dan gas karbondioksida secara cepat dan efisien (Retno et. al, 2011). S.cereviceae menghasilkan enzim zimase dan invertase. Enzim zimase berfungsi sebagai pemecah sukrosa menjadi monosakarida (glukosa). Enzim invertase selanjutnya mengubah glukosa menjadi bioetanol (Setyawati dan Rahma, 2013). Tujuan dari penelitian ini adalah untuk mengetahui kondisi massa dan waktu optimum yang dibutuhkan oleh S.cereviceae untuk mengkonversi kulit nenas (Ananas comosus Merr.), menjadi bioetanol. Juga Untuk mengetahui karakterisasi Bioetanol yang dihasilkan.

Penelitian ini bertujuan untuk mengetahui cara konversi nenas menjadi bioetanol serta mengetahui pengaruh waktu fermentasi dan massa ragi S.cereviceae terhadap jumlah etanol yang dihasilkan. Kulit nenas yang telah kering dihidrolisis menggunakan asam sulfat $\left(\mathrm{H}_{2} \mathrm{SO}_{4}\right)$, difermentasi dengan variasi waktu 2, 4 dan 6 hari dengan variasi masa ragi 20, 40 dan 60 gram. Etanol yang dihasilkan dimurnikan dengan proses destilasi. Kemudian kadar etanol dianalisis menggunakan alat kromatografi gas.

\section{METODOLOGI PENELITIAN}

Rancangan penelitian ini bertujuan untuk mengetahui pengaruh masa dan waktu $S$. Cereviceae terhadap volume dan kadar bioetanol yang dihasilkan. Kulit nenas diberikan perlakuan awal seperti pencucian, pemotongan, pengeringan dan penghalusan dengan menggunakan blender. Pembuatan media starter digunakanlah variasi $S$. cereviceae sebanyak 20 , 40 dan 60 gram. Pada tahapan hidrolisis kulit nenas menggunakan $\mathrm{H}_{2} \mathrm{SO}_{4} 1 \%$ sebanyak $150 \mathrm{ml}$ dan disterilisasi dengan autoclave pada suhu 121 ${ }^{\circ} \mathrm{C}$ selama 120 menit. Kemudian sampel disaring dan filtrat hasil dari hidrolisis dimasukkan ditambahkan media starter dan difermentasi dengan variasi waktu 2,4 dan 6 hari. Kemudian hasil dari fermentasi dimurnikan dengan cara didestilasi selama 1 jam dengan temperatur dibawah titik didih etanol yaitu sekitar $60-70{ }^{\circ} \mathrm{C}$ hingga didapat bioetanol murni.

\subsection{Pembuatan Media Starter}

Erlenmeyer yang berisi media starter diaduk secara manual agar dapat tercampur merata dan homogen. Kemudian media starter disimpan pada suhu $30^{\circ} \mathrm{C}$ selama 24 jam.

Di dalam erlenmeyer dibuat campuran antara amonium sulfat (nutrien), akuades, S.cereviceae dengan perbandingan seperti pada tabel berikut:

Tabel 1. Pembuatan Media Starter

\begin{tabular}{|c|c|c|c|}
\hline $\begin{array}{c}\text { Jenis } \\
\text { Starter }\end{array}$ & $\begin{array}{c}\text { Amonium } \\
\text { Sulfat } \\
\text { (gram) }\end{array}$ & $\begin{array}{c}\text { Akuades } \\
(\mathbf{m l})\end{array}$ & $\begin{array}{c}\text { S. } \\
\text { cereviceae } \\
\text { (gram) }\end{array}$ \\
\hline A & $\mathbf{1}$ & $\mathbf{3 0}$ & $\mathbf{2 0}$ \\
\hline B & $\mathbf{1}$ & $\mathbf{3 0}$ & $\mathbf{4 0}$ \\
\hline C & 1 & 30 & $\mathbf{6 0}$ \\
\hline
\end{tabular}

\subsection{Hidrolisis}

Larutan selulosa dibuat dengan menimbang 20 gram serbuk kulit nenas dan dilarutkan dengan $150 \mathrm{ml}$ asam sulfat $1 \%$ (Yusak, 2003). Larutan dihidrolisis pada suhu $115^{\circ} \mathrm{C}$ selama 1 jam. Kemudian didinginkan dan setelah hidrolisis kemudian disaring diambil filtratnya dan dilakukan uji kadar glukosa. Uji kadar glukosa dilakukan dengan menggunakan metode Iodometri.

Iodometri merupakan salah satu metode analisis kuantitatif volumetri secara oksidimetri dan reduksimetri melalui proses titrasi (W Haryadi, 1990). Titrasi oksidimetri adalah titrasi terhadap larutan zat pereduksi (reduktor) dengan larutan standar zat pengoksidasi (oksidator). Titrasi reduksimetri adalah titrasi terhadap larutan zat pengoksidasi (oksidator) dengan larutan standar zat pereduksi (reduktor). Oksidasi adalah suatu proses pelepasan satu elektron atau lebih atau bertambahnya bilangan oksidasi suatu unsur. Reduksi adalah suatu proses penangkapan sau elektron atau lebih atau berkurangnya bilangan oksidasi dari suatu unsur. Reaksi oksidasi dan reduksi berlangsung serentak, dalam reaksi ini oksidator akan direduksi dan reduktor akan dioksidasi sehingga terjadilah suatu reaksi sempurna.

Pada titrasi iodometri secara tidak langsung, natrium tiosulfat digunakan sebagai titran dengan indikator larutan amilum. Natrium tiosulfat akan 
bereaksi dengan larutan iodin yang dihasilkan oleh reaksi antara analit dengan larutan KI berlebih. Sebaiknya indikator amilum ditambahkan pada saat titrasi mendekati titik ekivalen karena amilum dapat membentuk kompleks yang stabil dengan iodin.

\subsection{Fermentasi}

Filtrat hasil hidrolisis diambil kemudian ditambahkan nutrien ammonium sulfat $\left(\mathrm{NH}_{4}\right)_{2} \mathrm{SO}_{4} 1$ gr dan akuades $30 \mathrm{ml}$. pH nya dikondisikan pada rentang 4 , sesuai dengan $\mathrm{pH}$ optimum dari $S$. Cereviceae. Selanjutnya dipasteurisasi pada suhu $120^{\circ} \mathrm{C}$ selama 15 menit lalu didinginkan. Ditambahkan ragi roti $(S$. cereviceae) dan kemudian diinkubasi secara an aerob pada suhu ruang dengan variasi waktu 2,4 dan 6 hari (Retno et. al, 2011).

\subsection{Destilasi}

Pemurnian bioetanol yang dihasilkan dilakukan dengan cara destilasi. Pemisahan dilakukan pada suhu $60-70^{\circ} \mathrm{C}$, suhu sangat berpengaruh pada proses pemisahan, karena suhu titik didih etanol yaitu $78,3^{\circ} \mathrm{C}$ dan suhu air $100^{\circ} \mathrm{C}$ maka etanol akan menguap terlebih dahulu dan terpisah dari komponen lain (Yonas et. al, 2014)

\section{HASIL DAN PEMBAHASAN \\ Hasil}

\section{a. Uji Glukosa}

Dari pengujian kadar glukosa yang dilakukan pada kulit nenas menggunakan metode iodometri didapatkan glukosa sebesar 2,10\% , seperti pada tabel 2.

Tabel.2 Uji Glukosa Pada Kulit Nenas

\begin{tabular}{|l|l|l|l|}
\hline Sampel & Karakteristik & $\begin{array}{c}\text { Hasil Uji } \\
(\boldsymbol{\%})\end{array}$ & $\begin{array}{c}\text { Metode } \\
\mathbf{U j i}\end{array}$ \\
\hline $\begin{array}{l}\text { Kulit } \\
\text { Nanas }\end{array}$ & Glukosa & 2,10 & Iodometri \\
\hline
\end{tabular}

\section{b. Rendemen}

Volume bioetanol yang dihasilkan dari proses hidrolisis dan fermentasi menggunakan S. Cereviceae masih sedikit, seperti pada tabel 3 .

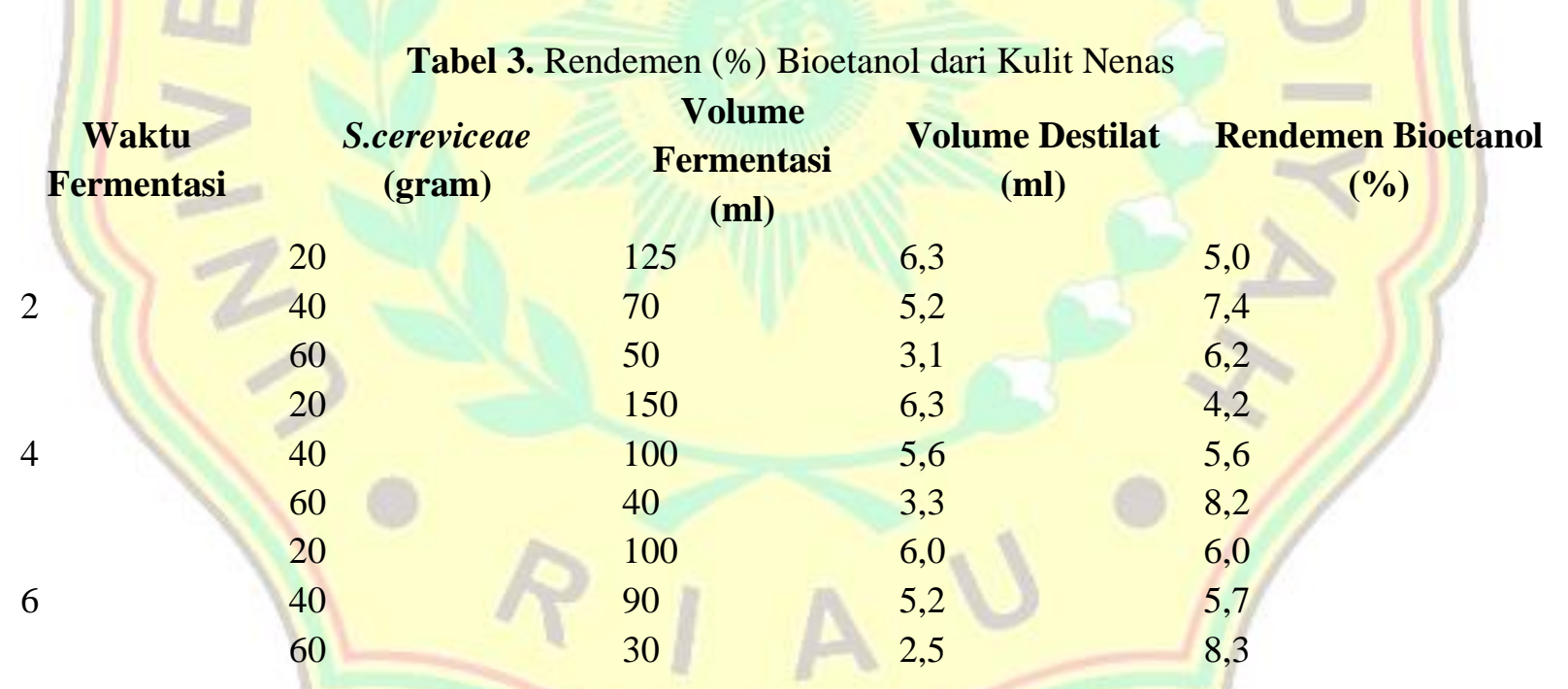

c. Kadar Etanol

Bioetanol dari hasil fermentasi yang telah dimurnikan dengan cara destilasi dan dikarekterisasi menggunakan kromatografi gas didapat kadar etanol yang cukup besar, seperti pada tabel 4 .

Tabel 4. Kadar Etanol Hasil Fermentasi Kulit Nenas

\section{Waktu \\ Fermentasi (hari)}

\section{S.cereviceae (gram)}

20
Volume Destilat (ml) Konsentrasi (\%)

6,3

26,3

SNI (min) (\%)

99,5 


\begin{tabular}{|c|c|c|c|c|}
\hline \multirow[t]{4}{*}{$\begin{array}{c}\text { Waktu } \\
\text { Fermentasi } \\
\quad \text { (hari) }\end{array}$} & $\begin{array}{c}\text { S.cereviceae } \\
\quad \text { (gram) }\end{array}$ & Volume Destilat (ml) & Konsentrasi (\%) & SNI (min) (\%) \\
\hline & 40 & 5,2 & 24,6 & \\
\hline & 60 & 3,1 & 22,4 & \\
\hline & 20 & 6,3 & 21,5 & \\
\hline \multirow[t]{3}{*}{4} & 40 & 5,6 & 22,9 & \\
\hline & 60 & 3,3 & 18,2 & \\
\hline & 20 & 6,0 & 13,9 & \\
\hline 6 & 40 & 5,2 & 12,4 & \\
\hline
\end{tabular}

\section{d. Konsentrasi Metanol}

Kadar bioetanol yang didapatkan lebih sedikit karena dari hasil fermentasi juga didapatkan metanol hasil dari karakterisasi kromatografi gas, seperti pada tabel 5.

Tabel 5. Konsentrasi Metanol Hasil Fermentasi Kulit Nenas

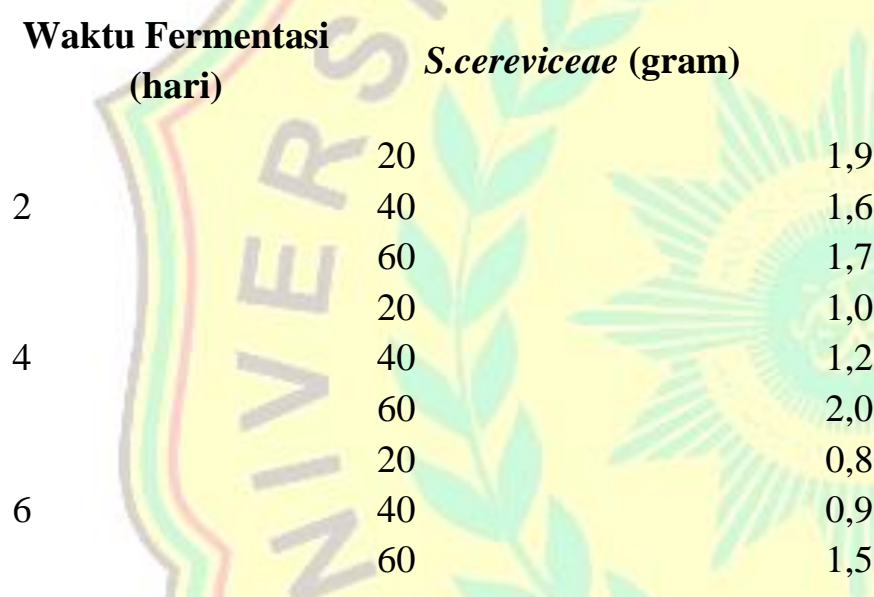

e. Keasaman Bioetanol

Selain dari Etanol dan metanol, fermentasi juga menghasilkan asam-asam organic. Dari
Konsentrasi (\%)

\section{SNI (min) $(\%)$}

1,9

1,6

1,7

1,0

1,2

2,0

0,8

0,9

1,5 variasi massa ragi dan variasi waktu fermentasi didapat angka asam seperti pada tabel 6

Tabel 6. Keasaman Bioetanol Hasil Fermentasi Kulit Nenas

\begin{tabular}{c|ccc}
$\begin{array}{c}\text { Waktu Fermentasi } \\
\text { (hari) }\end{array}$ & S.cereviceae (gram) & Keasaman Bioetanol & $\begin{array}{c}\text { SNI (maks) } \\
\text { (mg/It) }\end{array}$ \\
\cline { 2 - 3 } 2 & 20 & 70,7 & \\
& 40 & 70,5 & \\
60 & 70,2 & 30 \\
4 & 20 & 71,4 & \\
& 40 & 71,1 & \\
6 & 60 & 70,9 & \\
& 20 & 72,3 & \\
& 40 & 72,1 &
\end{tabular}




\section{Pembahasan}

\section{a. Hidrolisis}

Untuk hidolisis serat kulit nenas disini digunakan Asam sulfat $1 \%$ sebanyak 150 ml. ini ditambahkan ke dalam sampel untuk memperbesar kecepatan reaksi perombakan selulosa menjadi glukosa. Setelah sampel dihidrolisis dilakukan pengujian kadar glukosa menggunakan metode Iodometri. Pada penelitian ini kadar glukosa didapatkan hanya sebesar 2,10 $\%$ pada sampel 20 gram. Dari hasil tersebut dapat disimpulkan bahwa dari proses hidrolisis asam selulosa yang ada pada kulit nenas telah terurai menjadi monosakarida walaupun dalam hal ini kadar yang dihasilkan masih sedikit. Ini disebabkan masih adanya lignin yang terikat pada selulosa. Lignin sulit untuk didegradasi karena mempunyai struktur yang kompleks dan heterogen yang berikatan dengan selulosa dan hemiselulosa (Anindyawati, 2010).

\section{b. Fermentasi}

Fermentasi disini menggunakan kultur starter kering S.cereviceae. Oleh karena itu, starter tersebut diaktifkan terlebih dahulu dengan penambahan ammonium sulfat 1 gram sebagai nutrisi khamir dan akuades $30 \mathrm{ml}$ yang bertujuan agar khamir dapat bekerja secara optimum dalam proses fermentasi. Setelah itu dilakukan inkubasi dengan cara menutup rapat labu Erlenmeyer pada suhu ruangan. S.cereviceae merupakan salah satu khamir yang telah dikenal memiliki daya konversi gula menjadi etanol. Khamir ini memiliki enzim invertase yang berfungsi sebagai pemecah sukrosa menjadi monosakarida (glukosa dan fruktosa) dan enzim zimase yang berfungsi mengubah glukosa menjadi etanol (Nasrullah, 2009).

\section{c. Rendemen}

Perhitungan rendemen didapatkan dari selisih antara volume awal sebelum destilasi dikurang volume destilat dibagikan jumlah volume awal sebelum destilasi dikalikan $100 \%$. Hasil yang didapatkan, yaitu pada fermentasi 2 hari rendemen tertinggi yaitu $7,4 \%$ massa ragi 40 gram, fermentasi 4 hari yang tertinggi yaitu 8,3\% massa ragi 60 gram dan fermentasi 6 hari rendemen tertinggi yaitu 8,3\% massa ragi 60 gram. Pada gambar 1 dapat dilihat bahwa semakin besar massa ragi yang digunakan semakin banyak rendemen yang dihasilkan dan sebaliknya. Tingginya nilai rendemen yang berbanding terbalik dengan nilai etanol disebabkan karena semakin lama waktu fermentasi, maka semakin banyak etanol yang dikonversi menjadi asam.

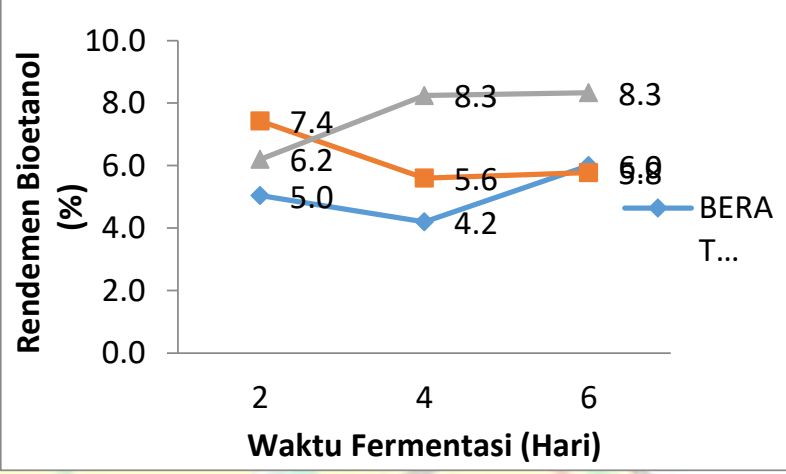

Gambar 1. Grafik Hubungan \% Rendemen Bioetanol Terhadap Waktu Fermentasi dan Masa Ragi

\section{d. Konsentrasi Etanol dari Hasil Fermentasi Kulit Nanas}

Penentuan kadar etanol yang telah didestilasi dalam sampel menggunakan Gas Kromatografi. Kromatografi merupakan suatu metode pemisahan dengan komponen-komponen yang akan dipisahkan terdistribusi diantara dua fase yaitu fase diam dan fase gerak. Etanol yang dianalisis terlebih dahulu dilakukan proses dehidrasi dengan bantuan kapur tohor yang bertujuan untuk mengikat molekul air yang terdapat pada bioetanol (Hendayana, 2000). Kadar etanol paling tinggi dihasilkan pada fermentasi 2 hari yaitu 26,3\% dengan massa ragi 20 gram, pada fermentasi 4 hari yaitu 22,9\% massa ragi 40 gram dan pada fermentasi 6 hari yaitu 13,9 \% massa ragi 20 gram. Dan dari keseluruhan hasil tersebut disimpulkan pada waktu fermentasi 2 hari, rata-rata kadar bioetanol yang dihasilkan lebih tinggi namun belum memenuhi standar mutu SNI $7390: 2012$, dimana kadar etanol minimal 99,5\%. Sedangkan kadar etanol terendah yang dihasilkan pada waktu fermentasi 6 hari. Semakin lama waktu 
fermentasi semakin sedikit bioetanol yang dihasilkan. Hal ini disebabkan nutrisi yang dibutuhkan untuk pembiakan sudah habis, akibatnya bakteri memakan alkohol hal ini ditunjukkan adanya pembentukan asam asetat. Proses ini dapat terlihat adanya gelembunggelembung udara pada sampel. (Retno et. al, 2011).

Variasi massa ragi, semakin banyak ragi yang ditambahkan semakin sedikit bioetanol yang dihasilkan. Massa ragi 60 gram rata-rata menghasilkan bioetanol yang sedikit. Semakin besar massa penambahan ragi semakin sedikit etanol yang dihasilkan, hal ini dikarenakan jumlah nutrisi yang tersedia tidak sebanding dengan jumlah S.cereviceae yang lebih banyak, sehingga kekurangan makanan yang mengakibatkan kinerja S.cereviceae menurun dan mengakibatkan kadar bioetanol yang dihasilkan sedikit juga. Pada Gambar 3.1 dapat dilihat perbandingan variasi waktu dan variasi massa ragi. Konsentrasi etanol yang dihasilkan belum memenuhi standar SNI yaitu minimal 99,5 $\%$. Hal ini kemungkinan karena massa sampel yang digunakan tidak skala besar sehingga untuk konversi glukosa dihasilkan sangat kecil. Pada saat proses fermentasi, konversi glukosa menjadi bioetanol menghasilkan etanol yang sedikit pula. Karena untuk mendapatkan bioetanol yang optimum harus memiliki kadar glukosa antara 14$18 \%$ (Nasrullah, 2009).

Pada kromatogram hasil pembacaan gas kromatografi terlihat puncak selain dari metanol dan etanol yaitu pada massa ragi 40 gram fermentasi 2 hari, 60 gram fermentasi 4 hari dan 20 gram fermentasi 6 hari, puncak tersebut dapat berupa debris yang timbul dari sistem lingkungan sekitar.

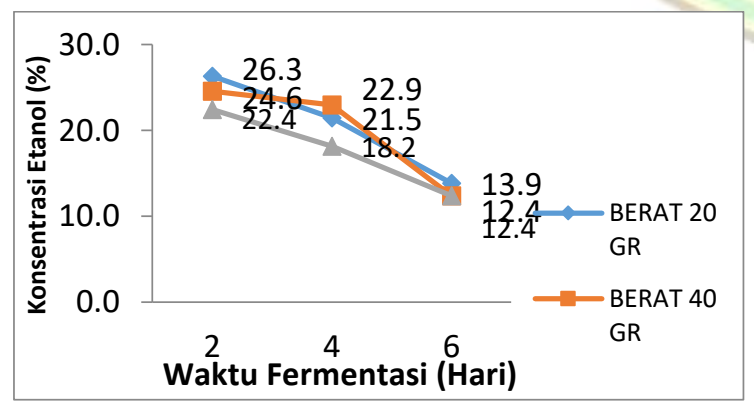

Gambar 2. Grafik Hubungan Kadar Etanol

Terhadap Waktu Fermentasi dan Masa Ragi

\section{e. Konsentrasi Metanol dari Hasil Fermentasi Kulit Nanas}

Konsentrasi metanol diperoleh karena metanol merupakan senyawa alkohol dengan 1 rantai karbon dengan titik didih $64^{\circ}-65^{\circ} \mathrm{C}$. Pada penelitian ini, pengujian kadar metanol juga menggunakan metode gas kromatografi. Hasil yang didapatkan yaitu pada fermentasi 2 hari, konsentrasi metanol yang tertinggi yaitu 1,9\% massa ragi 20 gram, pada fermentasi 4 hari yaitu $1,4 \%$ pada massa ragi 60 gram dan pada fermentasi 6 hari yaitu 1,0\% massa ragi 60 gram. Dari grafik tersebut, dapat dilihat rata-rata kadar metanol yang dihasilkan lebih rendah dibandingkan kadar etanol.

Dari grafik terlihat bahwa semakin besar konsentrasi metanol yang terbentuk maka diperlukan waktu inkubasi yang semakin singkat (2 hari) dan semakin lama waktu reaksi maka ada kemungkinan terjadi penguapan senyawa alkoholnya sehingga konsentrasi metanol akan semakin menurun, selain itu penurunan konsentrasi metanol juga bisa disebabkan karena bahan atau nutrisi di dalam media sudah habis, sehingga menyebabkan mikroorganisme banyak yang mati karena $\mathrm{pH}$ yang semakin asam dan tingkat keasaman yang semakin tinggi.

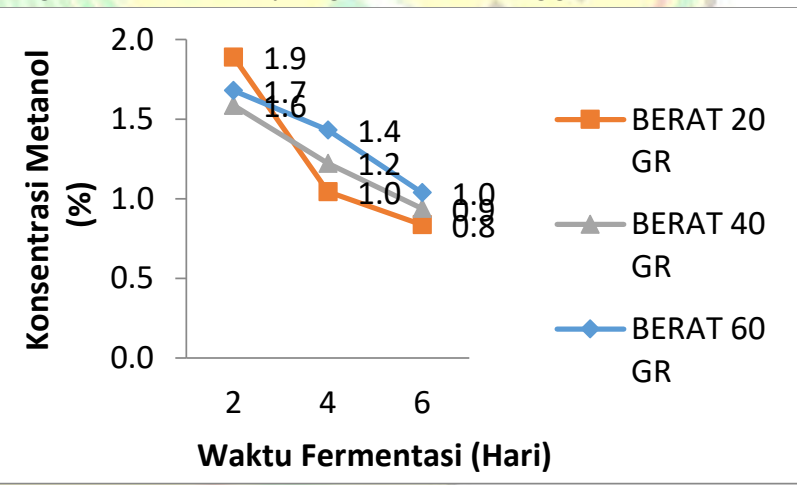

Gambar 3. Grafik Hubungan Konsentrasi Metanol Terhadap Waktu Fermentasi dan Masa Ragi

\section{f. Identifikasi Keasaman Bioetanol sebagai Asam Asetat}

Berdasarkan perhitungan yang mengacu pada SNI 7390:2012 tentang keasaman sebagai asam asetat dapat diketahui bahwa perlakuan lama fermentasi $(2,4,6$ hari) dengan penggunaan masa ragi 20, 40 dan 60 gram berpengaruh pada nilai 
keasaman bioetanol dari kulit nenas. Standar maksimum untuk keasaman berdasarkan SNI adalah 30 .

Dapat terlihat pada gambar 3.2 di bawah bahwa keasaman bioetanol pada 2 hari fermentasi lebih rendah nilainya jika dibandingkan dengan 4 dan 6 hari fermentasi. Pada 2 hari fermentasi nilai keasaman dengan masa ragi 20, 40 dan 60 gram adalah 70,2 mg/l, 70,4 mg/l dan 70,7 mg/l pada 4 hari fermentasi nilai keasaman mengalami kenaikan pada masa ragi 20, 40 dan 60 gram adalah sebesar 70,9 mg/l, 71,1 mg/l dan 71,4 mg/l dan pada 6 hari fermentasi nilai keasaman pada masa ragi 20, 40 dan 60 gram adalah sebesar 71,9 $\mathrm{mg} / \mathrm{l}, 72,1 \mathrm{mg} / \mathrm{l}$ dan $72,2 \mathrm{mg} / \mathrm{l}$. Tingkat keasaman dengan 2 hari fermentasi lebih rendah karena berbanding terbalik dengan konsentrasi etanol maksimum yang dihasilkan pada waktu tersebut yaitu $26,3 \%, 24,6 \%$ dan $22,4 \%$.

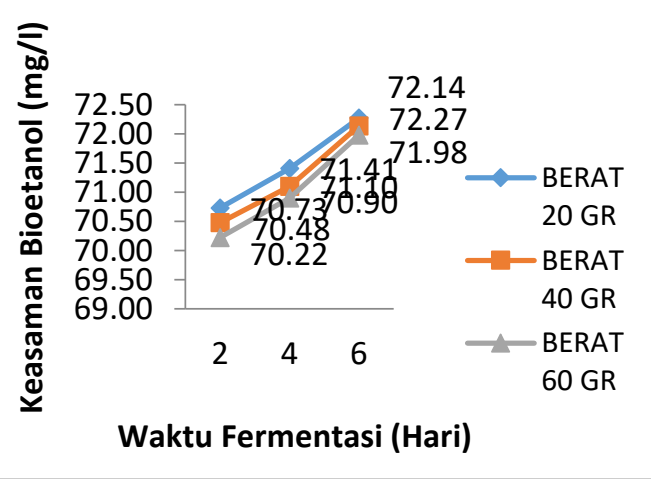

Gambar 4. Grafik Hubungan Keasaman Terhadap Waktu Fermentasi dan Masa Ragi

Kadar Etanol yang didapat dari penelitian ini lebih baik dari yang dilakukan oleh penelitian sebelumnya (Setyawati dan Rahman, 2012) yaitu membuat bioetanol dari kulit buah nenas dengan variasi penambahan massa S.cereviceae dan waktu fermentasi. Variabel yang digunakan adalah perubahan massa S.cereviceae 20,30, dan 40 gram, pH fermentasi 4 dan 5 dengan waktu fermentasi 2, 4, 6, 8 dan 10 hari. Dari analisis yang dilakukan terhadap hasil penelitian diperoleh hasil kadar glukosa awal sari kulit nenas $8,5325 \%$, kadar glukosa tertinggi dari fermentasi adalah $8,4275 \%$, pada penambahan 30 g S.cereviceae dan waktu fermentasi 2 hari. Kadar bioetanol tertinggi yang diperoleh hanya sebesar 3,965\% pada penambahan $30 \quad \mathrm{~g}$ S.cereviceae dan waktu fermentasi 10 hari.

Tapi penelitian yang dilakukan Oktaviani, 2013, mendapatkan kadar etanol yang lebih besar, dimana waktu maksimum proses fermentasi untuk memproduksi bioetanol dengan metode SSF (Solid State Fermentation) dan mempelajari kinetika pertumbuhan Zymomonas Mobilis terhadap variasi ukuran partikel substrat berupa slurry, $1 \times 1 \mathrm{~cm}$ dan $2 \times 2 \mathrm{~cm}$. Kondisi lingkungan pertumbuhan Zymomonas mobilis diatur pada $\mathrm{pH} 5$ dan temperatur $30^{\circ} \mathrm{C}$, dan waktu optimumnya 24 jam. Analisa kadar etanol yang dihasilkannya menggunakan alkoholmeter dan perhitungan jumlah sel dengan metode turbidity menggunakan spektrofotometer UV untuk menentukan kinetika sel pertumbuhan Zymomonas mobilis.

Dari Penelitian yang dilakukan Pramita et. al, 2013, terhadap kulit nenas juga menjadi bioetanol menggunakan simultan sakarifikasi dan Proses Fermentasi (SSF) diperoleh nilai tertinggi bioetanol diperoleh hanya sebesar $14 \%$ atau sama dengan $110.502 \mathrm{mg} / \mathrm{ml}$, untuk variasi pada $10 \%$ inokulum dan proses fermentasi 4 hari.

\section{KESIMPULAN}

1. Kondisi optimum yang dibutuhkan S.cereviceae secara anaerob untuk mengkonversi kulit nenas menjadi bioetanol adalah dengan masa ragi 20 gram dan fermentasi selama 2 hari, dimana konsentrasi bioetanol yang didapatkan adalah sebesar $26,3 \%$.

2. Lama waktu fermentasi tidak berbanding lurus dengan kadar bioetanol yang dihasilkan namun bergantung pada persediaan nutrisi dan kondisi lingkungan. Kadar etanol yang dihasilkan semakin menurun pada fermentasi hari ke 4 dan ke 6 , dengan urutan hari ke-2 (26,3\%), hari ke-4 (22,9 $\%)$ dan hari ke-6 sebesar (13,9\%).

\section{DAFTAR PUSTAKA}

Ali, H.K.Q., Zulkali, M.M.D., 2013. Ethanol production from date syrup with flocculent yeast: optimization study. 
Environ. Prog. Sustain. Energy 32, 818823.

Hendayana, S., Maekinnu, S.S., Adji., 2000. Kimia Analitik. Universitas Terbuka : Jakarta.

Komarayati, Sri., Gusmailina., 2005. Prospek Bioetanol Sebagai Pengganti Minyak Tanah. Pusat Penelitian Dan Pengembangan Hasil Hutan : Bogor.

Nasrullah., 2009. Hidrolisis Asam dan Enzimatis Pati Ubi Jalar Menjadi Glukosa Sebagai Substrat Fermentasi Etanol. Skripsi. Uin Syarif Hidayatullah. Jakarta.

Oktaviani, Reni., Chairul., Amraini, Said Zul., 2013. Produksi Etanol Dari Limbah Kulit Nanas Dengan Metode SSF Terhadap Variasi Waktu Dan Variasi Ukuran Partikel Substrat. Jurnal Rekayasa Bioproses. Teknik Kimia : Universitas Riau.

Pramita, Dwi Laura., Yenie, Elvi., Muria, Sri Rezeki., 2013. Pembuatan Bioetanol Dari Kulit Nenas Menggunakan Enzim Selulase Dan Yeast Sacharomyces cerevisiae Dengan Proses Simultaneous Sacharification And Fermentation (SSF)
Terhadap Variasi Konsentrasi Inokulum Dan Waktu Fermentasi. Jurnal Rekayasa Bioproses. Teknik Kimia : Universitas Riau.

Retno, Dyah Tri., Nuri, Wasir., 2011. Pembuatan Bioetanol Dari Kulit Pasang. Prosiding Seminar Nasional Teknik Kimia "Kejuangan". Teknik Kimia UPN: Yogyakarta.

Setyawati, H., Rahma, N.A., 2013. Bioethanol from pineapple peel with Sacharomyces cereviceae mass and fermentation time variation. Jurnal teknik kimia. Institut Teknologi Nasional : Malang.

SNI 7390:2012, Bioetanol Terdenaturasi Untuk Gasohol, Badan Standarisasi Nasional. Jakarta.

W. Haryadi, (1990). Ilmu Kimia Analitik Dasar. Gramedia : Jakarta

Yonas, Ikbal Mohammad., Isa, Ishak., dan Iyabu, Hendri., 2014. Pembuatan Bioetanol Berbasih Sampah Organik Batang Jagung. Jurnal Pendidikan Kimia. Fakultas MIPA: Universitas Negeri Gorontalo. 